\title{
Utilization of Processed Pine Needle Powder in Broiler Chicken Diets
}

\author{
Eunjoo Kim ${ }^{1 *}$, Ji Young Jung ${ }^{2 *}$, Hyun Min Cho ${ }^{1}$, Samiru Sudharaka Wickramasuriya ${ }^{1}$, Shemil Pyrian Maceline ${ }^{1}$, \\ Taeg Kyun Shin ${ }^{1}$, Beomgyu $\mathrm{Kim}^{1}$ and Jung Min $\mathrm{Heo}^{3+}$ \\ ${ }^{I}$ Student, Department of Animal Science and Biotechnology, Chungnam National University, Daejeon 34134, Republic of Korea \\ ${ }^{2}$ Researcher, Division of Environmental Forest Science / Institute of Agriculture and Life Science, Gyeongsang National University, \\ Jinju 52828, Republic of Korea \\ ${ }^{3}$ Professor, Department of Animal Science and Biotechnology, Chungnam National University, Daejeon 34134, Republic of Korea
}

\begin{abstract}
This study examined the effects of dietary processed pine needle tree powder (PPNP) on growth performance, visceral organ parameters, ileal digestibility, blood metabolites and ileal morphology of broiler chickens for 5-week after hatch. In total, 220 1-day-old male Ross 308 broiler chicks were randomly allocated to 30 pens (seven birds per pen), and each pen was assigned to one of five dietary treatments, a diet without PPNP (control) and diets with $0.5 \%, 1.0 \%, 1.5 \%$ and $2.0 \%$ PPNP. The body weight and feed intake were measured weekly. One bird from each pen was selected randomly and gently euthanized to collect the blood, visceral organs and digesta samples on 2, 3 and 5 week of age. Birds fed $2.0 \%$ PPNP showed decreased $(P<0.05)$ overall body weight, average daily gain and average daily feed intake compared to those fed control, 0.5 and $1.0 \%$ PPNP. The small intestine length increased $(P<0.05)$ as the level of PPNP in the diet increased. A deeper crypt depth was observed $(P<0.05)$ when birds fed 2.0\% PPNP compared to those fed the control diet at week 2 . A higher V:C ratio was observed $(P<0.05)$ in birds fed 1.0\% PPNP than in those fed other treatments at week 3. Ileal protein digestibility improved $(P<0.05)$ when birds fed $0.5 \%$ and $1.0 \%$ PPNP compared to that in those fed the control diet at week 3 . The feed conversion ratio, ileal dry matter digestibility and blood urea nitrogen and cholesterol, and gizzard and ceca weights were not affected $(P>0.05)$ by supplementation of any levels of PPNP. These results demonstrated that inclusion of PPNP in broiler diets could be a possible factor in improving overall growth performance suggesting early gut development when $1 \%$ PPNP is supplemented.
\end{abstract}

(Key words: broiler, processed pine needle powder, growth performance, ileal digestibility)

\section{INTRODUCTION}

Improving gut health for broiler could be greatly responsible for final production rate to the market. Many strategies (e.g., antibiotics, feeding modulations, and, enzymes) are incorporated to protect gut from external infectious, and to ensure that broiler would have maximum genetic potential productivity (Yang et al., 2009). However, public interests associated with use of antimicrobial compounds in the diets have increased because of very negative effect of antibiotics resistance in national health (Heuer et al., 2007). Therefore, alternative antibiotics have evolved depending on its producing area, price and efficacy.

For example, pine needle tree, Pinus densiflora, abundantly distributed in Korea and China, and its by-products produced commonly by infected pine needles with forest pests (Lee et al., 2013). With these by-products, South Korea produces liquid fertilizer for horticulture (Kim et al., 2008) and powder prebiotics for human and animals (Guri et al., 2006). Generally, pine needle trees contain high contents of tannins (Pfister et al., 1992), and subsequent simple process conducted to reduce its anti-nutritional factors such as steam explosion, hot water extraction and grinding.

Processed pine tree powder (PPNP) used for a feed supplement in the present study containing higher cellulose and hemicellulose contents (Ofomaja et al., 2009) is classified as non-starch polysaccharides and able to have a critical function as prebiotics in poultry production. In addition, PPNP is commercially available at a low price and its consumer demand has been increasing because compatible biological characteristics (Lee, 2003; Kim and Chung, 2011). According to Kim et al. (2012), broilers fed $1 \%$ or $2 \%$ pine tree powder

\footnotetext{
* These authors contributed equally to this work.

† To whom correspondence should be addressed : jmheo@cnu.ac.kr
} 
showed a reduction in serum total cholesterol and improved meat quality. Moreover, pine needle extracts have anti-microbial and anti-inflammatory activities against pathogen, stimulating the growth of beneficial gut bacteria particularly Enterococcus spp. and Bipidobacterium spp. (Lee, 2003; Kim and Shin, 2005; Smullen et al., 2007). However, scientific literatures not adequately proved the benefits of PPNP for broiler production.

Because reliable data of PPNP for broiler is not fully explored, the present study was carried out to determine PPNP supplementation for broiler on growth performance, visceral organ parameters, blood metabolites and nutrient digestibility during entire 5 weeks after hatch. We hypothesized that the birds fed PPNP would show improved growth performance compared with control-fed birds and that these effects would be associated with beneficial effects of PPNP for gut health.

\section{MATERIALS AND METHODS}

The Animal Ethics Committee of the Chungnam National University (CNU-811) approved all experimental procedures regarding this study.

\section{Experimental Design, Animals, Housing}

The experiment was arranged as a completely randomized design of five dietary treatments with six replicates (seven chickens per pen), respectively. A total of 210-day-old male Ross 308 broiler chickens were used, and one replicate placed in wire-floor pens $\left(0.85 \times 0.55 \times 0.35 \mathrm{~m}^{3}\right)$. Chickens were evenly distributed to ensure that there were no statistical differences between initial body weights. The lighting regimen used was $24 \mathrm{~L}: 0 \mathrm{D}$ of light at first 3 days, and then applied $23 \mathrm{~L}$ : $1 \mathrm{D}$ of light during days 4 to 35 . The temperature was maintained at $3 \pm 1{ }^{\circ} \mathrm{C}$ from day 0 to 3 , and was then gradually decreased $3{ }^{\circ} \mathrm{C}$ weekly until $24^{\circ} \mathrm{C}$ was reached at day 21 . Fresh water and feed were provided on an ad libitum basis.

\section{Processed Pine Needle Tree Powder}

Timbered pine trees were chipped $(2 \times 3 \mathrm{~cm})$ and dried for 7 days at room temperature, and then exploded with steam (Severity factor Ro $3.94,200^{\circ} \mathrm{C}, 10$ minute) to maximize the water holding capacity and oil absorptive power. Then, hot water extraction was carried out to extract sugar, tannin and phenols, and consequently filtration was conducted to refine its physical characteristics such as swelling capacity and oil holding capacity. Finally, solid parts were obtained and dried at room temperature, and then grinded to 80 mesh to maximize the physical property.

\section{Experimental Diets}

Basal diets were formulated with large proportion of corn and soybean meal according to Ross 308 broiler nutrient specification (Table 1; Aviagen, 2014). The basal diets were divided and different levels of PPNP were added and diluted. The supplementation of PPNP was delivered as top-dressing. Chickens received one of the five dietary treatments as follows: 1) basal diet without PPNP; 2) basal diet with $0.5 \%$ PPNP; 3) basal diet with 1.0\% PPNP; 4) basal diet with $1.5 \%$ PPNP; 5) basal diet with 2.0\% PPNP. All experimental diets were different only with a small amount of PPNP. To estimate the ileal digestibility of nutrients, chickens fed diets supplemented with $0.3 \%$ of chromium oxide as indigestible marker throughout the experimental period.

\section{Data Collection}

Mortality was recorded daily while body weights were measured individually and weekly. Feed consumption were recorded on a pen basis to calculate the average daily gain, average daily feed intake and feed conversion ratio.

\section{Post-Mortem Procedures and Sample Collec- tion}

For sample collection, six chickens per treatment were selected, and euthanized by cervical dislocation after blood collection. At week 2 and 3, blood samples were collected from jugular vein in EDTA coated vacutainer tubes. At week 2 and 5, gizzard and ceca were dissected and weighed and small intestine (duodenum through ileum) were measured its length. At week 2, 3 and 5, ileal contents were collected from Meckel's diverticulum to ileocecal junction smoothly and immediately stored in collection cup at $-80^{\circ} \mathrm{C}$. Five cm fragments of ileum, anterior portion of ileocecal junction, were obtained for morphology analyses (Murakami et al., 2007). 
Table 1. Composition of basal diets (as-fed basis)

\begin{tabular}{|c|c|c|}
\hline Ingredients (\%) & $\begin{array}{c}\text { Starter } \\
(1 \sim 3 \text { week })\end{array}$ & $\begin{array}{c}\text { Grower } \\
(3 \sim 5 \text { week })\end{array}$ \\
\hline Corn & 44.05 & 56.45 \\
\hline Wheat & 5.9 & - \\
\hline Wheat bran & 8.15 & 5.95 \\
\hline Soybean meal, $44 \%$ & 36.0 & 30.6 \\
\hline Vegetable oil & 1.6 & 2.8 \\
\hline Limestone & 1.5 & 1.5 \\
\hline Monocalcium phosphate & 1.7 & 1.6 \\
\hline Salt & 0.3 & 0.3 \\
\hline Vitamin and mineral premix ${ }^{1}$ & 0.3 & 0.3 \\
\hline DL-Methionine & 0.2 & 0.2 \\
\hline Chromium oxide & 0.3 & 0.3 \\
\hline $\begin{array}{c}\text { Metabolizable } \\
\text { energy (kcal/kg) }\end{array}$ & 3,100 & 3,200 \\
\hline Crude protein $(\%)$ & 23 & 20 \\
\hline Calcium (\%) & 1.1 & 1.1 \\
\hline $\begin{array}{c}\text { Available } \\
\text { phosphate (\%) }\end{array}$ & 0.45 & 0.41 \\
\hline Lysine (\%) & 1.3 & 1.1 \\
\hline Methionine (\%) & 0.5 & 0.5 \\
\hline Cystein (\%) & 0.3 & 0.3 \\
\hline
\end{tabular}

${ }^{1}$ Vitamin and mineral premix provided the following nutrients (per kg of air-dry diet): Vitamins: A 12,000 IU, D 33,000 IU, E $15 \mathrm{mg}, \mathrm{K} 2 \mathrm{mg}$, thiamine $2 \mathrm{mg}$, riboflavin $6 \mathrm{mg}$, pyridoxine $2 \mathrm{mg}$, calcium pantothenate $0.03 \mathrm{mg}$, folic acid $0.2 \mathrm{mg}$, niacin $45 \mathrm{mg}$, biotin $0.15 \mu \mathrm{g}$. Minerals: calcium $0.5 \%$, Co $0.5 \mathrm{mg}$ (as cobalt sulphate), $\mathrm{Cu} 10 \mathrm{mg}$ (as copper sulphate), iodine $0.9 \mathrm{mg}$ (as potassium iodine), iron $80 \mathrm{mg}$ (as ferrous sulphate), Mn 80 $\mathrm{mg}$ (as manganous oxide), Se $0.2 \mathrm{mg}$ (as sodium selenite), $\mathrm{Zn}$ $80 \mathrm{mg}$ (as zinc oxide).

2 The values are calculated according to the values of feedstuffs in NRC (1994).

\section{Sample Preparation and Laboratory Analyses}

For ileal digestibility, ileal digesta samples were analyzed for dry matter and crude protein according to the methods of AOAC (1984). Chromium dioxide concentration in the digesta samples were determined using the method of Fenton and Fenton (1979).
Blood samples were centrifuged $\left(3,000 \times \mathrm{g}, 10 \mathrm{~min}\right.$ and $\left.4^{\circ} \mathrm{C}\right)$ to obtain plasma. Blood urea nitrogen and total cholesterol level from plasma samples were then analyzed by Enzymatic assay method using an Automatic Analyzer 7180 (Hitachi, Japan). Small intestine tissue samples were fixed in $10 \%$ buffered formalin, processed with paraffin embedding method. For staining of slide section, hematoxylin and eosin staining technique were subjected as described Bancroft and Stevens (2015). Villus height and crypt depth were taken in $\mu \mathrm{m}$ and they were observed with an inverted microscope (Eclipse TE2000; Nikon Instruments Inc., Melville, NY 11747-3064, USA) equipped with a digital imaging system (NIS-Elements Viewer Software Version 4.20; NIS Elements, Nikon, USA).

\section{Statistical Analyses}

Each pen used as the experimental unit for growth parameters. Selected individual chickens were considered as experimental units for blood metabolites, visceral organ weights, gut morphology and digestibility. All data subjected to ANOVA. Tukey's multiple range test was used for significant differences at the $5 \%$ levels. Statistical procedures were performed using IBM SPSS Statistics 24 software (IBM Corp., Armonk, NY, USA).

\section{RESULTS}

\section{Growth Performance}

Mortality was not related to any dietary treatments. The effect of experimental treatments on growth performance of broiler chickens is summarized in Table 2. Birds fed $0.5 \%$ and $1.0 \%$ PPNP had not significantly difference $(P>0.05)$ in body weight compared to those fed control diet while birds fed $1.5 \%$ and $2.0 \%$ PPNP had lower $(P<0.05)$ body weight at week 2 and 3. Similarly, birds fed control, $0.5 \%$ and $1.0 \%$ PPNP diets increased average daily feed intake $(P<0.05)$ compared to those were in $1.5 \%$ and $2.0 \%$ PPNP at week 2 and 3 .

\section{Visceral Organ Parameters}

The effect of inclusion of PPNP on visceral organ parameters is shown in Table 3. Gizzard and ceca weights in proportion to body weights were not affected $(P>0.05)$ by 
Table 2. Effect of inclusion of wood powder on growth performance in broiler chickens ${ }^{1}$

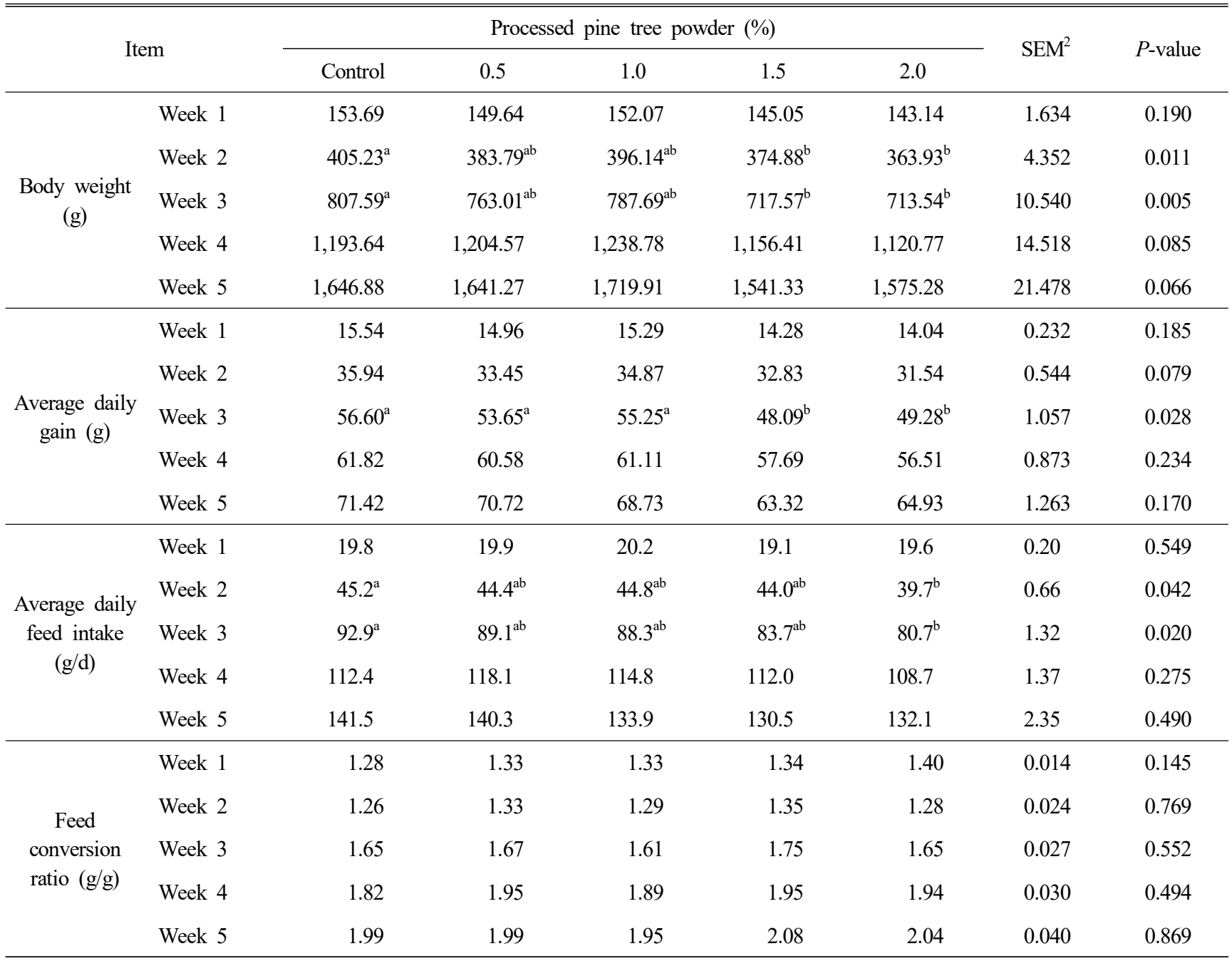

${ }^{1}$ Results are mean with 6 replicates per treatment.

${ }^{2}$ Pooled standard error of mean.

${ }^{\mathrm{a}, \mathrm{b}}$ Means within the same row without common superscripts are significantly different $(P<0.05)$.

PPNP supplementation. Small intestine lengths expressed as $\mathrm{cm} / 100 \mathrm{~g} /$ body weight were higher $(P<0.05)$ in birds fed $2.0 \%$ PPNP compared to those fed $0.5 \%$ PPNP at week 2 .

Birds fed control, $1.0 \%$ and $1.5 \%$ PPNP were not differ in small intestine length at week 2 .

\section{Blood Parameters}

The blood parameters affected by inclusion of PPNP is shown in Table 4. Blood urea nitrogen and cholesterol were not affected $(P>0.05)$ by PPNP supplementation.

\section{Ileal Morphology}

Effect of inclusion of PPNP on ileal morphology is summarized in Table 5. At week 2, ileal crypt depth was increased $(P<0.05)$ as PPNP contents were increased. In addition, birds fed $2.0 \%$ PPNP had a numerical trend $(P<0.10)$ in lower $\mathrm{V}$ : $\mathrm{C}$ ratio compared to those were in other treatments.

\section{Ileal Digestibility}

Ileal digestibility affected by inclusion of PPNP in diet is shown in Table 6. Birds fed 2.0\% PPNP in the diet had significantly lower $(P<0.05)$ ileal crude protein digestibility at week 2 and 3. Ileal dry matter and energy digestibility in 
Table 3. Effect of inclusion of wood powder on organ weights in broiler chickens ${ }^{1}$

\begin{tabular}{|c|c|c|c|c|c|c|c|c|}
\hline \multirow{2}{*}{ Iter } & & \multicolumn{5}{|c|}{ Processed pine tree powder $(\%)$} & \multirow{2}{*}{$\mathrm{SEM}^{2}$} & \multirow{2}{*}{$P$-value } \\
\hline & & Control & 0.5 & 1.0 & 1.5 & 2.0 & & \\
\hline \multirow{2}{*}{ Gizzard (\%) } & Week 2 & 2.59 & 2.55 & 2.58 & 2.47 & 2.43 & 0.051 & 0.839 \\
\hline & Week 5 & 1.27 & 1.29 & 1.33 & 1.24 & 1.23 & 0.027 & 0.811 \\
\hline \multirow{2}{*}{ Ceca $(\%)$} & Week 2 & 0.54 & 0.55 & 0.44 & 0.53 & 0.58 & 0.021 & 0.277 \\
\hline & Week 5 & 0.40 & 0.42 & 0.42 & 0.42 & 0.41 & 0.012 & 0.983 \\
\hline \multirow{2}{*}{$\begin{array}{l}\text { Small intestine } \\
(\mathrm{cm} / 100 \mathrm{~g} / \mathrm{BW})\end{array}$} & Week 2 & $29.83^{\mathrm{ab}}$ & $27.50^{\mathrm{b}}$ & $27.87^{\mathrm{ab}}$ & $31.11^{\mathrm{ab}}$ & $35.11^{\mathrm{a}}$ & 0.687 & 0.001 \\
\hline & Week 5 & 9.27 & 9.40 & 9.17 & 9.55 & 9.93 & 0.185 & 0.754 \\
\hline
\end{tabular}

${ }^{1}$ Results are mean with 6 replicates per treatment.

${ }^{2}$ Pooled standard error of mean.

a,b Means within the same row without common superscripts are significantly different $(P<0.05)$.

Table 4. Effect of inclusion of wood powder on blood parameters in broiler chickens ${ }^{1}$

\begin{tabular}{|c|c|c|c|c|c|c|c|c|}
\hline \multirow{2}{*}{ Item } & & \multicolumn{5}{|c|}{ Processed pine tree powder $(\%)$} & \multirow{2}{*}{$\mathrm{SEM}^{2}$} & \multirow{2}{*}{$P$-value } \\
\hline & & Control & 0.5 & 1.0 & 1.5 & 2.0 & & \\
\hline \multirow{2}{*}{$\begin{array}{l}\text { Blood urea nitrogen } \\
\qquad(\mathrm{mg} / \mathrm{dL})\end{array}$} & Week 2 & 1.20 & 1.21 & 1.36 & 1.27 & 1.30 & 0.038 & 0.733 \\
\hline & Week 3 & 1.02 & 1.10 & 1.01 & 0.80 & 0.98 & 0.071 & 0.814 \\
\hline \multirow{2}{*}{$\begin{array}{c}\text { Blood total } \\
\text { cholesterol }(\mathrm{mg} / \mathrm{dL})\end{array}$} & Week 2 & 127.9 & 124.2 & 114.8 & 108.2 & 101.2 & 3.57 & 0.071 \\
\hline & Week 3 & 118.4 & 118.0 & 117.2 & 116.9 & 115.3 & 1.63 & 0.986 \\
\hline
\end{tabular}

${ }^{1}$ Results are mean with 6 replicates per treatment.

${ }^{2}$ Pooled standard error of mean.

Table 5. Effect of inclusion of wood powder on ileal morphology in broiler chickens ${ }^{1}$

\begin{tabular}{|c|c|c|c|c|c|c|c|c|}
\hline & \multirow{2}{*}{ Item } & \multicolumn{5}{|c|}{ Processed pine tree powder $(\%)$} & \multirow{2}{*}{$\mathrm{SEM}^{2}$} & \multirow{2}{*}{$P$-value } \\
\hline & & Control & 0.5 & 1.0 & 1.5 & 2.0 & & \\
\hline \multirow{3}{*}{ Week 2} & Villus $(\mu \mathrm{m})$ & 179.79 & 262.40 & 231.06 & 236.69 & 200.04 & 13.87 & 0.396 \\
\hline & Crypt $(\mu \mathrm{m})$ & $44.34^{\mathrm{ab}}$ & $37.88^{\mathrm{a}}$ & $50.23^{\mathrm{ab}}$ & $48.81^{\mathrm{ab}}$ & $61.63^{\mathrm{b}}$ & 2.75 & 0.050 \\
\hline & $\mathrm{V}: \mathrm{C}^{3}$ & 4.14 & 7.36 & 4.60 & 4.77 & 3.35 & 0.48 & 0.069 \\
\hline \multirow{3}{*}{ Week 5} & Villus $(\mu \mathrm{m})$ & 448.55 & 435.51 & 463.35 & 433.31 & 416.56 & 18.89 & 0.968 \\
\hline & Crypt $(\mu \mathrm{m})$ & 63.31 & 54.45 & 55.35 & 62.90 & 63.31 & 2.95 & 0.809 \\
\hline & $\mathrm{V}: \mathrm{C}$ & 7.27 & 8.03 & 8.25 & 7.12 & 6.62 & 0.32 & 0.521 \\
\hline
\end{tabular}

\footnotetext{
${ }^{1}$ Results are mean with 6 replicates per treatment.

${ }^{2}$ Pooled standard error of mean.

a,b Means within the same row without common superscripts are significantly different $(P<0.05)$.
}

chickens were not related to inclusion of PPNP in the diet.

\section{DISCUSSION}

The main purpose of this study was to investigate whether the supplementation of PPNP could improve growth performance along with enhancing healthy gut parameters could be 
Table 6. Effect of inclusion of wood powder on nutrient digestibility in broiler chickens ${ }^{1}$

\begin{tabular}{|c|c|c|c|c|c|c|c|c|}
\hline \multirow{2}{*}{\multicolumn{2}{|c|}{ Item }} & \multicolumn{5}{|c|}{ Processed pine tree powder $(\%)$} & \multirow{2}{*}{$\mathrm{SEM}^{2}$} & \multirow{2}{*}{$P$-value } \\
\hline & & Control & 0.5 & 1.0 & 1.5 & 2.0 & & \\
\hline \multirow{3}{*}{ Dry matter } & Week 2 & 0.77 & 0.75 & 0.77 & 0.73 & 0.70 & 0.010 & 0.065 \\
\hline & Week 3 & 0.81 & 0.82 & 0.82 & 0.78 & 0.78 & 0.007 & 0.153 \\
\hline & Week 5 & 0.85 & 0.84 & 0.83 & 0.83 & 0.82 & 0.004 & 0.233 \\
\hline \multirow{3}{*}{ Crude protein } & Week 2 & $0.72^{\mathrm{ab}}$ & $0.74^{\mathrm{b}}$ & $0.73^{\mathrm{ab}}$ & $0.70^{\mathrm{ab}}$ & $0.69^{\mathrm{a}}$ & 0.007 & 0.034 \\
\hline & Week 3 & $0.77^{\mathrm{bc}}$ & $0.78^{\mathrm{c}}$ & $0.77^{\mathrm{c}}$ & $0.73^{\mathrm{ab}}$ & $0.72^{\mathrm{a}}$ & 0.009 & 0.005 \\
\hline & Week 5 & 0.81 & 0.80 & 0.79 & 0.77 & 0.78 & 0.005 & 0.072 \\
\hline \multirow{3}{*}{ Energy } & Week 2 & 0.71 & 0.72 & 0.73 & 0.69 & 0.70 & 0.007 & 0.523 \\
\hline & Week 3 & 0.74 & 0.73 & 0.75 & 0.70 & 0.71 & 0.009 & 0.275 \\
\hline & Week 5 & 0.75 & 0.77 & 0.79 & 0.74 & 0.71 & 0.011 & 0.267 \\
\hline
\end{tabular}

${ }^{1}$ Results are mean with 6 replicates per treatment.

${ }^{2}$ Pooled standard error of mean.

${ }^{\mathrm{a} \sim \mathrm{c}}$ Means within the same row without common superscripts are significantly different $(P<0.05)$.

changed in broiler chickens.

In the present study, although there was no significant difference in feed conversion ratio, body weight and daily gain and feed intake improved when broiler chickens fed PPNP at specific levels (i.e., less than 1.0\%). Consequently, birds fed $2.0 \%$ PPNP had significantly lower feed consumption compared to other treatments. Despite we did not conduct a palatability test, it could be a result from the distinctive aroma compounds of PPNP which may effect on feed consumption. Kim and Chung (2011) analyzed volatile components of pine needle powder using Gas Chromatography and founded a total of 230 compounds which may account for the unique aroma. Similarly, Açıkgöz et al. (2005) demonstrated that propolis extracted from pine trees had a unique odor, therefore this property can be the reason for decreased feed intake when broilers fed dietary propolis at high levels. Moreover, since pine needle had strong sensory cues, some vertebrate species, particularly rats, rejected to consume the diet contained pine needle oil (Wager-Page et al., 1995). Nevertheless, its beneficial effects on other parameters, we should consider the amount of PPNP to prevent negative effect on feed consumption.

Alterations in the gut development during growing period will have great repercussion on final productivity of broiler chickens such as body weight to the market age. Deeper crypts of ileum indicate that faster gut tissue turnover to renew of the villus. In addition, shorten villus and deeper crypts may represent that poor nutrient absorption and lower performance (Caspary, 1992; Xu et al., 2003). On the other hand, the higher $\mathrm{V}: \mathrm{C}$ ratio refers to improved digestibility, elevating digestive enzyme activities (Baurhoo et al., 2007; Zeng et al., 2015). On top of that our study, birds fed $0.5 \%$ PPNP had lower crypt depth of ileum and trend of highest $\mathrm{V}: \mathrm{C}$ ratio among the treatments among other treatments at week 2 and it could be a reflection outcome from PPNP supplementation which had impact on gut development. Major component of PPNP is insoluble fiber, and it acts as prebiotics which is beneficially affect the host by stimulating the growth of intestinal bacteria and gut activities, prolonging the exposure of digesta to mechanical digestion (Pourabedin and Zhao, 2015). Similarly, PPNP supplementation significantly affected on ileal protein digestibility both week 2 and 3. It may be associated with shallow crypt depth at the same period. Further, at week 5, there was a numerical trend in greater final body weight when birds fed $1.0 \%$ PPNP compared to other treatments and this result may be partly associated with positive result in $\mathrm{V}: \mathrm{C}$ ratio and ileal protein digestibility. 
Despite its poor absorptive ability, insoluble fiber are widely used for development in gastrointestinal tract of nonruminant animals. The heaviest gizzard and increased gut volume were exhibited when birds fed additional insoluble fiber in the diet, prolonging the digesta retention time, which leads production of digestive enzymes and fluids (Nir et al., 1994; Ravindran et al., 2006; Svihus, 2011). Even though insoluble fiber is not digested with endogenous enzymes, it could be partially degraded by bacterial fermentation in hindgut, triggering changes in the composition of the microflora, and enlarging the gut capacity (Starck, 1999). In the present study, the length of small intestine was expended as the amount of PPNP in the diet was increased at week 2. This result is in accordance with JøRgensen et al. (1996) who suggested that birds adopted to increased dietary fiber had increased the size of the digestive system, particularly the length and weight of the intestine. Based on our results of body weight, gut morphology and organ parameters, PPNP supplementation at $1.0 \%$ level could act as prebiotics, and be beneficial for early gut development in broiler production.

Donsbough et al. (2010) suggested that blood urea nitrogen can be utilized as an indicator of protein digestibility. In the present study, ileal protein digestibility altered by supplemented PPNP while none of the treatments affected blood urea nitrogen. Even though we do not know exact mechanism to explain our result, we assumed our inclusion levels were too low to affect blood metabolites. Kim et al. (2012) reported that broiler fed $2 \%$ fine needle powder showed lower blood cholesterol compared to birds fed control diet. Similarly, Kim (2011) reported that total cholesterol and LDL-cholesterol concentration were lower when birds fed $0.9 \%$ pine needle powder in the diet. In the present study, on the other hand, total cholesterol levels were not different among the treatment, and it may be partially explained by the average cholesterol levels were lower and in normal range than above mentioned reports so that these were not vary significantly affected by inclusion of PPNP.

In conclusion, the effect of PPNP is still comparatively unexplored area. The present study indicated that supplementation of $1.0 \%$ PPNP in the diet showed improved overall body weight and ileal morphology while $2.0 \%$ PPNP in the diet negatively affected on overall growth and physical gut development. This study indicated that supplementation of PPNP for broiler chickens may have potential benefits on starter period, working as prebiotics.

\section{ACKNOWLEDGEMENTS}

This research was financially supported by the research fund of Chungnam National University.

\section{REFERENCES}

Açıkgöz Z, Yücel B, Altan Ö 2005 The effects of propolis supplementation on broiler performance and feed digestibility. Arch Geflügelk 69(3):117-122.

AOAC 1984 Official Methods of Analysis. 4th ed. pages 1-45. Association of Official Analytical Chemists, Arlington, VA.

Aviagen 2014. Ross 308 broiler. Broiler performance objectives [Internet]. Available from: http://en.aviagen.com/assets/ Tech_Center/Ross_Broiler/Ross-308-Broiler-Nutrition-Spe cs-2014r17-EN.pdf

Bancroft J, Stevens A 1996 Theory and Practice of Histological Techniques. Churchill Livingstone, New York. Yayım tarihi 19.

Baurhoo B, Phillip L, Ruiz-Feria C 2007 Effects of purified lignin and mannan oligosaccharides on intestinal integrity and microbial populations in the ceca and litter of broiler chickens. Poult Sci 86(6):1070-1078.

Caspary WF 1992 Physiology and Pathophysiology of Intestinal Absorption. Oxford University Press.

Donsbough A, Powell S, Waguespack A, Bidner T, Southern L 2010 Uric acid, urea, and ammonia concentrations in serum and uric acid concentration in excreta as indicators of amino acid utilization in diets for broilers. Poult Sci 89(2):287-294.

Fenton TW, Fenton M 1979 An improved procedure for the determination of chromic oxide in feed and feces. Can $\mathrm{J}$ Anim Sci 59(3):631-634.

Guri A, Kefalas P, Roussis V 2006 Antioxidant potential of six pine species. Phytother Res 20(4):263-266.

Heuer H, Smalla K 2007 Manure and sulfadiazine synergistically increased bacterial antibiotic resistance in soil 
over at least two months. Environ Microbiol 9(3):657666.

JøRgensen H, Zhao XQ, Knudsen KEB, Eggum BO 1996 The influence of dietary fibre source and level on the development of the gastrointestinal tract, digestibility and energy metabolism in broiler chickens. Br J Nutr 75(3): 379-395.

Kim JG, Seo DJ, Yoon SL 2008 A study on the selective control of pine wilt disease and utilization of damaged trees. Pages 242-245. In: Proceeding of Korean Soc Forest Sci Conf.

Kim JS, Chung HY 2011 Profiling of volatile components using gas chromatography-mass spectrometry in commercial pine needle (Pinus densiflora S. and Z.) powder. Prev Nutr Food Sci 16(1):45-54.

Kim YJ, Kim CM, Choi JH, Choi IH 2012 Effect of dietary mugwort (Artemisia vulgaris L.) and pine needle powder (Pinus densiflora) on growth performance, serum cholesterol levels, and meat quality in broilers. Afr J Biotechnol 11(55):11998-12004.

Kim YJ 2011 Effects of dietary supplementation of pine needle powder on carcass characteristics and blood cholesterol contents of broiler chicken. Korean J Poult Sci 38(1):51-57.

Kim YS, Shin DH 2005 Volatile components and antibacterial effects of pine needle (Pinus densiflora S. and Z.) extracts. Food Microbiol 22(1):37-45.

Lee E 2003 Effects of powdered pine needle (Pinus densiflora Seib et Zucc.) on serum and liver lipid composition and antioxidative capacity in rats fed high oxidized fat. $\mathrm{J}$ Korean Soc Food Sci Nutr 32(6):926.

Lee H, Jeon H, Han JI, Kim YJ, Kim CH, Kim DY 2013 Unexplained perioperative hypotension in a patient treated with pine needle extract. Open J Anesthesiol 3(1):8.

Murakami A, Sakamoto M, Natali M, Souza L, Franco J 2007 Supplementation of glutamine and vitamin E on the morphometry of the intestinal mucosa in broiler chickens. Poult Sci 86(3):488-495.

Nir I, Hillel R, Shefet G, Nitsan Z 1994 Effect of grain particle size on performance. 2. Grain texture interactions. Poult Sci 73(6):781-791.

Ofomaja A, Naidoo E, Modise S 2009 Removal of copper
(II) from aqueous solution by pine and base modified pine cone powder as biosorbent. J Hazard Mater 168(2-3):909917.

Pfister JA, Adams DC, Wiedmeier RD, Cates RG 1992 A adverse effects of pine needles on aspects of digestive performance in cattle. J Range Manage 45:528-533.

Pourabedin M, Zhao X 2015 Prebiotics and gut microbiota in chickens. FEMS Microbiol Letters 362.

Ravindran V, Wu Y, Thomas D, Morel P 2006 Influence of whole wheat feeding on the development of gastrointestinal tract and performance of broiler chickens. Aust $\mathrm{J}$ Agric Res 57(1):21-26.

Smullen J, Koutsou G, Foster H, Zumbé A, Storey D 2007 The antibacterial activity of plant extracts containing polyphenols against Streptococcus mutans. Caries Res 41(5): 342-349.

Starck JM 1999 Phenotypic flexibility of the avian gizzard: Rapid, reversible and repeated changes of organ size in response to changes in dietary fibre content. J Exp Biol 202(22):3171-3179.

Svihus B 2011 The gizzard: Function, influence of diet structure and effects on nutrient availability. World's Poult Sci J 67(2):207-224.

Wager-Page SA, Mason JR, Aronov E, Epple G 1995 The role of sensory cues and feeding context in the mediation of pine-needle oil's repellency in prairie voles. In: Proceeding National Wildlife Research Center Repellents Conference.

Xu Z, Hu C, Xia M, Zhan X, Wang M 2003 Effects of dietary fructooligosaccharide on digestive enzyme activities, intestinal microflora and morphology of male broilers. Poult Sci 82(6):1030-1036.

Yang Y, Iji PA, Choct M 2009 Dietary modulation of gut microflora in broiler chickens: A review of the role of six kinds of alternatives to in-feed antibiotics. World's Poult Sci J 65(1):97-114

Zeng Z, Zhang S, Wang H, Piao X 2015 Essential oil and aromatic plants as feed additives in non-ruminant nutrition: A review. J Anim Sci Biotechnol 6(1):7.

Received Jun. 22, 2018, Revised Sep. 7, 2018, Accepted Sep. 7, 2018 